\title{
Spirometry and obstructive lung disease in Manitoba
}

\author{
NR Anthonisen MD ${ }^{1}, \mathrm{~N} \mathrm{Dik}^{2}, \mathrm{~J}_{\text {Manfreda }} \mathrm{MD}^{1,2}, \mathrm{LL}$ Roos $\mathrm{PhD}^{2}$ \\ Section of Respiratory Diseases, and Departments of ${ }^{1}$ Internal Medicine \\ and ${ }^{2}$ Community Health Sciences, Faculty of Medicine, University of Manitoba \\ and the Health Sciences Centre, Winnipeg, Manitoba
}

NR Anthonisen, N Dik, J Manfreda, LL Roos. Spirometry and obstructive lung disease in Manitoba. Can Respir J 2001;8(6):421-426.

BACKGROUND: Spirometry, the measurement of forced expiratory volume in $1 \mathrm{~s}$ and forced vital capacity, is recommended in the diagnosis and management of the obstructive lung diseases asthma and chronic obstructive pulmonary disease (COPD). The present report describes spirometry use in Manitoba and tests the hypothesis that regional spirometry use correlates with the prevalence of physiciandiagnosed obstructive lung diseases.

METHODS: Spirometry is remunerated on a fee-for-service basis by Manitoba Health. Like other physician services, billing data include a diagnosis, patient identifiers, as well as the patient's sex, date of birth and residential postal code. Physician billings for spirometry for 1991 to 1998 were analyzed, comparing data with billings for physician visits for obstructive diseases. Four age groups were examined, as were income quintiles in Winnipeg, Manitoba. In addition, the prevalence of physician-diagnosed obstructive diseases were compared with spirometry rates in 49 service use areas of the province.

RESULTS: Annually, about 3\% of the Manitoba population underwent spirometry, and in aggregate, about $14 \%$ underwent spirometry during the eight years of the study. Rates in Winnipeg were higher than in the remainder of the province. Spirometry rates did not increase with time, and people who underwent spirometry had 1.4 to 1.7 tests/year. In children, higher income quintiles were tested more than lower income quintiles, while in adults, income quintiles were tested with equal frequency. People with obstructive lung disease accounted for about $75 \%$ of those tested, and in people with these diagnoses, the likelihood of testing increased approximately linearly with the number of physician visits for asthma or COPD. Children with asthma were tested less often than adults, and adults with asthma or both asthma and COPD were tested more often than those with COPD alone. In adults with asthma or asthma and COPD who had more than 10 physician visits for these diagnoses, testing rates were more than $70 \%$, and multiple tests were common. In patients labelled with COPD only and with more than 20 physician visits, about one-third did not undergo spirometry. In children aged five to 14 years and in adults 15 to 44 years old, regional spirometry rates correlated well with regional asthma rates. Regional spirometry rates also correlated significantly with regional rates of asthma and/or COPD in people older than 34 years old.

INTERPRETATION: Spirometry use is considerably higher in patients with asthma than in patients with COPD, suggesting that guidelines are followed more closely in patients with asthma, and that many patients are labelled with COPD without appropriate documentation. Spirometry use is apparently indicative of physician interest in the problem of obstructive lung diseases.

Key Words: Asthma; Chronic obstructive pulmonary disease; Guidelines; Spirometry

pour le résumé, voir page suivante 


\section{Spirométrie et maladies respiratoires obstruc- tives au Manitoba}

CONTEXTE : La spirométrie, mesure du volume expiratoire maximal en une seconde et de la capacité vitale, est recommandée pour le diagnostic et le traitement des maladies respiratoires obstructives (MRO) comme l'asthme et les bronchopneumopathies chroniques obstructives (BPCO). Le présent rapport fait état du recours à la spirométrie au Manitoba et tente de vérifier l'hypothèse selon laquelle l'utilisation régionale de la spirométrie est en corrélation avec la prévalence des MRO diagnostiquées par les médecins.

MÉTHODE : La spirométrie est un service rémunéré à l'acte par le ministère de la Santé du Manitoba. Comme pour les autres services médicaux, les données relatives à la facturation comprennent les éléments suivants : le diagnostic, l'identificateur du patient, le sexe, la date de naissance et le code postal. Nous avons analysé les factures des médecins envoyées entre 1991 et 1998 pour des spirométries et comparé les données recueillies aux factures des médecins pour des consultations ayant trait à une MRO. Nous avons examiné quatre groupes d'âge ainsi que les quintiles des revenus à Winnipeg, au Manitoba. En outre, la prévalence des MRO diagnostiquées par les médecins a été comparée aux taux de spirométrie relevés dans 49 zones de service dans la province.

RÉSULTATS : Environ $3 \%$ de la population du Manitoba a subi, chaque année, une spirométrie et $14 \%$ dans l'ensemble pour les huit années à l'étude. Les taux à Winnipeg étaient plus élevés qu'ailleurs en province. Les taux de spirométrie n'augmentaient pas avec le temps et les patients soumis à l'examen ont subi de 1,4 à
1,7 épreuve par année. Chez les enfants, plus de tests ont été effectués dans les quintiles de revenus élevés que dans les quintiles de revenus modestes, tandis que, chez les adultes, les tests ont été effectués à une fréquence égale dans tous les quintiles. Les personnes souffrant d'une MRO constituaient environ $75 \%$ des patients examinés, et la probabilité de subir un test pour les patients atteints de ce type de maladie augmentait de façon presque linéaire avec le nombre de consultations pour de l'asthme ou une BPCO. Les enfants asthmatiques ont subi moins d'épreuves que les adultes, et les adultes souffrant d'asthme ou d'asthme et d'une BPCO étaient examinés plus souvent que ceux qui ne présentaient qu'une BPCO. Parmi les adultes souffrant d'asthme ou d'asthme et d'une BPCO qui ont consulté un médecin plus de 10 fois pour leur maladie, on a enregistré des taux d'examen supérieurs à $70 \%$ et les reprises étaient fréquentes. Quant aux patients atteints d'une BPCO seulement et comptant plus de 20 consultations, un tiers environ n'avait pas subi de spirométrie. Chez les enfants âgés entre 5 et 14 ans et les adultes âgés entre 15 et 44 ans, les taux régionaux de spirométrie correspondaient bien aux taux régionaux d'asthme. Les taux régionaux de spirométrie étaient également en étroite relation avec les taux régionaux d'asthme ou de BPCO chez les adultes de plus de 34 ans.

INTERPRÉTATION : Le recours à la spirométrie est beaucoup plus élevé chez les patients souffrant d'asthme que chez les patients atteints d'une BPCO, ce qui donne à penser que les lignes de conduite sont suivies plus rigoureusement pour les asthmatiques et que le diagnostic de BPCO chez de nombreux patients ne repose pas sur des données appropriées. Le recours à la spirométrie semble révélateur de l'intérêt des médecins à l'égard des MRO.
$\mathrm{S}^{\mathrm{p}}$ pirometry, the measurement of the forced expiratory volume in $1 \mathrm{~s}\left(\mathrm{FEV}_{1}\right)$ and forced vital capacity $(\mathrm{FVC})$, is the basic lung function test recommended in all patients suspected of having obstructive pulmonary disease. Both the Canadian and American Thoracic Societies have published guidelines recommending spirometry in these diseases as an initial diagnostic tool and as a key method of assessment in follow-up (1-4). It is not clear how commonly spirometry is used in the medical community at large. In Manitoba, spirometry is remunerated on a fee-for-service basis, and the physician must include the patient's health care number in billing for the service. Bills are submitted to Manitoba Health, which administers the provincial health care plan. Thus, the Manitoba Health database describes, generally speaking, who has undergone spirometric testing, and this can be related to other physician services that also identify the patient and include a diagnostic label. We used the Manitoba Health database to assess the degree of use of spirometry, with a focus on spirometry use in patients with diagnoses of asthma and chronic obstructive pulmonary disease (COPD).

We also anticipated that the use of spirometry would show substantial regional variation and related this variation to the prevalence of physician-diagnosed obstructive lung diseases, testing the hypothesis that spirometry use is a marker of the likelihood of the diagnosis. That is, if spirometry were important in the diagnosis of obstructive disease or if spirometry use indicated heightened diagnostic sensitivity to obstructive disease, then the prevalence of obstructive diseases should correlate with spirometry use among communities.

\section{METHODS}

As noted above, Manitoba Health maintains a database of physician services that includes a patient's personal health insurance number, sex, date of birth and residential postal code. These can be compared with the Manitoba Population Registry, also maintained by Manitoba Health. After approval from the University of Manitoba's Committee on the Ethics of Human Experimentation and from the Access Committee of Manitoba Health, data files were obtained with unidentifiable personal health insurance numbers of Manitobans who had undergone spirometry and who had received physician services for obstructive lung diseases during the years 1991 to 1998, inclusively.

The Manitoba physicians' fee schedule includes three tests that involve spirometry. 'Simple spirometry' is the measurement of the FEV 1 and FVC. 'Forced expiration' includes measurement of the maximum midexpiratory flow rate in addition to the $\mathrm{FEV}_{1}$ and FVC. 'Expiratory flow-volume curve' includes measurements of instantaneous expiratory flows, as well as the FEV 1 and FVC. These billings were analyzed without distinguishing among them; when more than one test on the same day was billed, all but the first test were discarded, so that only one test per day was counted.

Spirometry billings for 1991 to 1998 were examined year by year and over the eight years combined. When combined data were related to the provincial population, analyses was restricted to people who were Manitoba residents in 1998, noting the prevalence and frequency of spirometry in these people over the previous eight years. Spirometry data were analyzed as functions of sex and age, income quintile, place 


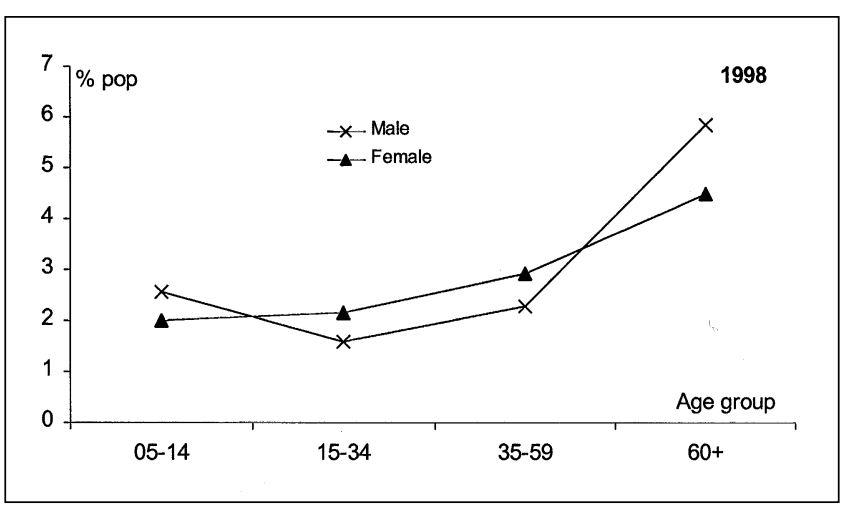

Figure 1) Spirometry rates in Manitoba in 1998 according to age and sex. The ordinate indicates the percentage of the relevant population that underwent spirometry in 1998, and the abscissa notes the age groups considered

of domicile and place where spirometry was performed. Age groups studied were five to 14 years, 15 to 34 years, 34 to 59 years and older than 60 years. Place of domicile was defined as either in Winnipeg, Manitoba or elsewhere in the province (termed rural), except in the analysis of small area variation, for which 49 service use areas were used that were previously defined in studies of Manitoba health care use (5). The place where spirometry was performed was defined by physician billings as either being performed by Winnipeg physicians or those who practised elsewhere. The influence of income quintile was studied only in Winnipeg. Patients' postal codes were related to census tracts with known average family income; these were divided into quintiles, so that a patient's home postal code signified an income quintile. In rural areas, family income may vary considerably in a single postal code, so that a single figure for average family income is less representative than in Winnipeg.

The lung diseases studied were asthma (International Classification of Diseases Ninth Revision [ICD-9] code 493); bronchitis not specified as acute or chronic (ICD-9 code 490); and COPD, including chronic bronchitis (ICD-9 code 491), emphysema (ICD-9 code 492) and chronic airway obstruction (ICD-9 code 496). The number of physician visit claims for each of these diagnoses was enumerated for each patient over the eight years of the study. When data aggregated over eight years were related to the provincial population, only residents of Manitoba in 1998 were considered. Claims were grouped as to number and diagnoses (bronchitis, asthma and COPD). Often, patients were labelled as having more than one of these diseases. These patients were segregated according to their diagnostic labels: asthma and bronchitis, asthma and COPD, bronchitis and COPD, and all three diagnoses together.

Income quintiles were analyzed for linear trends, and service areas were compared using linear regression. Slopes and differences among age groups and regions were compared using $t$ testing. $\mathrm{P}<0.05$ was considered statistically significant.

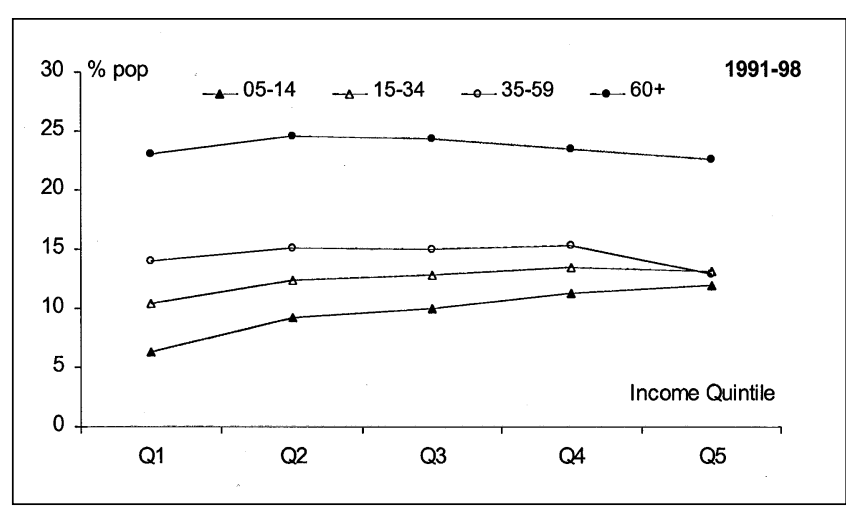

Figure 2) Spirometry rates according to income quintile $(Q)$ (abscissa) in Winnipeg over the eight years of study. Q1 is the lowest income quintile, Q5 the highest. The ordinate is the percentage of individuals living in Winnipeg in 1998 who were tested. Data from the four age groups studied are shown

\section{RESULTS}

In each of the eight years examined, about $3 \%$ of Manitobans aged five years and older underwent spirometry. The average annual rate was significantly $(\mathrm{P}<0.0001)$ higher in Winnipeg residents than in rural residents $(3.5 \%$ compared with $2 \%$ ), and in both groups of residents, the rates changed little with time. Of the residents of Manitoba in 1998, approximately $13 \%$ of those aged five years and older underwent spirometry at some point during the previous eight years $15 \%$ for residents of Winnipeg and 10\% for residents of rural areas. Over the eight-year study period, Winnipeg residents about $60 \%$ of the provincial population - accounted for about $70 \%$ of all spirometry performed in the province, which was almost always performed in Winnipeg. About one-half of the spirometric testing of rural residents was performed in Winnipeg as well. Figure 1 shows spirometry rates in the province in 1998 according to age group and sex. Rates differed little in the younger three age groups and increased in people older than 60 years. In the pediatric age group and in those older than 60 years, more men were tested than women, and the reverse was true for those between the ages 15 and 59 years. Similar patterns were observed in other years in people from both Winnipeg and rural areas. Patients who underwent spirometry averaged 1.4 to 1.7 tests/year, counting only one test per day; the highest figures applied to the oldest age group. The number of tests per year per patient did not vary over time and were not different between residents of Winnipeg and residents of rural areas.

Figure 2 shows spirometry use in Winnipeg residents analyzed according to income quintile. The data show the percentage of residents of Winnipeg in 1998 that had at least one test over the eight years of the study. In children, there was a significant linear trend, with spirometry more common in high income quintiles than in low income quintiles $(\mathrm{P}=0.011)$. In the other income groups, systematic differences according to income quintile were not evident.

Of people aged five years and older who lived in Manitoba in 1998, 39\% were diagnosed at least once during 


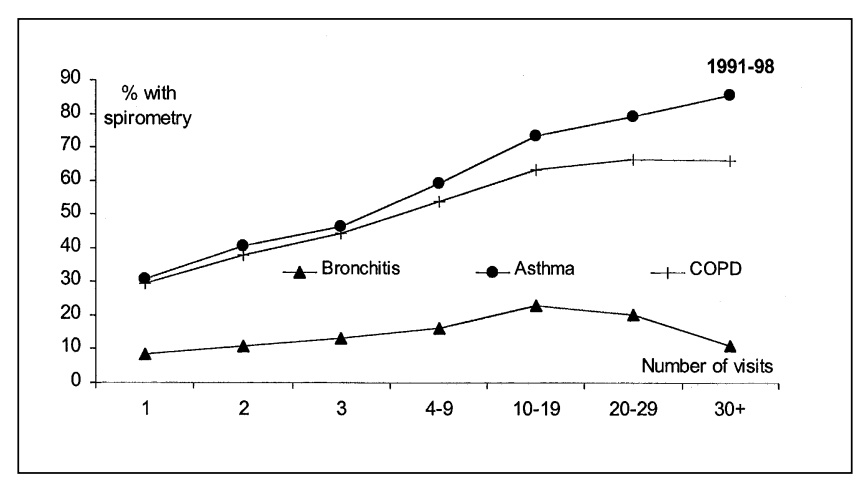

Figure 3) Percentage of patients with diagnostic labels of bronchitis, asthma and chronic obstructive pulmonary disease (COPD) that underwent spirometry (ordinate) over the eight years of the study (1991 to 1998) as a function of the number of physician visits (abscissa) for these diagnoses. Data from patients with more than one of these diagnoses are not shown

the preceding eight years as having bronchitis, asthma or COPD - with $40 \%$ diagnosed in Winnipeg and $37 \%$ in rural areas. Bronchitis and asthma were common in all age groups, and COPD was uncommon in people younger than 35 years of age. During the study period, about $87 \%$ of children and over $74 \%$ of adults who underwent spirometry had physician claims for one of these diagnoses; these percentages did not differ between Winnipeg and rural areas.

The likelihood of spirometric testing increased more or less linearly with the number of physician visits for obstructive disease (examples are shown in Figure 3). Of patients who had only one claim for obstructive disease, less than $30 \%$ underwent spirometry, while about $50 \%$ of patients with four to nine physician visits for asthma or COPD underwent spirometry. About $80 \%$ of patients with more than 20 claims for asthma underwent spirometry, while for COPD, this was the case in about $60 \%$ of patients. Patients with claims for both asthma and COPD had spirometry rates similar to those with asthma alone, given a similar number of visits to physicians. In patients labelled with bronchitis only, spirometry rates were substantially lower (Figure 3), and in patients with diagnoses of asthma or COPD, the additional label of bronchitis did not influence spirometry rates. Therefore, bronchitis was not analyzed further as a separate diagnostic category, but physician visits for bronchitis in patients labelled with COPD or asthma were enumerated as visits for obstructive disease.

In all diagnostic categories, the rate of testing was 5\% to $10 \%$ higher in Winnipeg residents than the provincial average, while that of rural residents was lower. In adults, testing rates for common obstructive diseases varied little among age groups. Testing rates for asthma were lower in children aged five to 14 years than in older age groups.

Table 1 shows the number of spirometric tests performed on different days over the eight-year study period in people aged 15 years or older with obstructive disease. The testing rate increased with the number of physician visits. Multiple tests were more common in patients labelled with asthma or asthma and COPD than in patients labelled with COPD only. More COPD patients did not have any tests, and among patients who underwent spirometry, patients with COPD underwent fewer tests than those labelled with asthma or both asthma and COPD.

For the population living in each of 49 service use areas in 1998, the percentages of people who underwent spirometry and who had physician-diagnosed obstructive disease in the preceding eight years were estimated. In northern areas with scattered settlements, $2 \%$ to $3 \%$ of the population underwent spirometric testing during 1991 to 1998, while in some other service use areas, this was true of nearly $25 \%$ of the population. Spirometry rates in several small southern communities were higher than in Winnipeg. Among service use areas, spirometry rates were compared with the frequency of asthma in children aged five to 14 years and in people aged 15 to 34 years. In people aged 35 years and older, spirometry rates were compared with the frequency of people labelled with COPD, asthma or both.

In children, spirometry rates varied from $1 \%$ to $2 \%$ to nearly $14 \%$ among service use areas, while the rate of asthma diagnosis varied from $9 \%$ to $27 \%$. Asthma frequency was correlated with the frequency of spirometry $(r=0.55$,

\section{TABLE 1}

\section{Percentage of people aged 15 years and older tabulated by diagnostic group, number of visits and number of} spirometry tests

\begin{tabular}{|c|c|c|c|c|c|c|c|c|c|c|c|c|c|c|c|}
\hline \multirow{2}{*}{$\begin{array}{l}\text { Number of } \\
\text { spirometric } \\
\text { tests }\end{array}$} & \multicolumn{5}{|c|}{$\begin{array}{l}\text { Number of visits for } \\
\text { asthma patients }(n)\end{array}$} & \multicolumn{5}{|c|}{$\begin{array}{l}\text { Number of visits for } \\
\text { COPD patients (n) }\end{array}$} & \multicolumn{5}{|c|}{$\begin{array}{l}\text { Number of of visits for } \\
\text { asthma and COPD patients (n) }\end{array}$} \\
\hline & $\begin{array}{c}2-3 \\
(23,692)\end{array}$ & $\begin{array}{c}4-9 \\
(25,006)\end{array}$ & $\begin{array}{r}10-19 \\
(8383)\end{array}$ & $\begin{array}{l}20-29 \\
(1927)\end{array}$ & $\begin{array}{c}30+ \\
(1277)\end{array}$ & $\begin{array}{c}2-3 \\
(14,546)\end{array}$ & $\begin{array}{c}4-9 \\
(12,598)\end{array}$ & $\begin{array}{r}10-19 \\
(3826)\end{array}$ & $\begin{array}{r}20-29 \\
(1110)\end{array}$ & $\begin{array}{c}30+ \\
(1275)\end{array}$ & $\begin{array}{c}2-3 \\
(2126)\end{array}$ & $\begin{array}{c}4-9 \\
(6294)\end{array}$ & $\begin{array}{r}10-19 \\
(5392)\end{array}$ & $\begin{array}{l}20-29 \\
(2561)\end{array}$ & $\begin{array}{c}30+ \\
(3828)\end{array}$ \\
\hline 0 & 55.9 & 43.0 & 28.2 & 19.3 & 12.5 & 62.8 & 52.5 & 42.7 & 35.6 & 31.3 & 46.5 & 37.3 & 26.9 & 22.2 & 14.9 \\
\hline 1 & 24.6 & 22.5 & 17.4 & 12.7 & 9.2 & 21.0 & 21.0 & 19.5 & 15.1 & 12.9 & 25.3 & 21.3 & 16.8 & 12.9 & 9.4 \\
\hline 2 & 11.0 & 13.9 & 13.0 & 10.0 & 7.0 & 8.9 & 11.9 & 11.7 & 11.1 & 9.3 & 14.1 & 15.1 & 14.6 & 11.3 & 7.8 \\
\hline 3 & 4.8 & 8.1 & 9.6 & 9.1 & 6.4 & 3.7 & 6.3 & 7.9 & 8.2 & 6.8 & 6.6 & 9.4 & 9.2 & 8.7 & 6.5 \\
\hline $4-9$ & 3.5 & 11.9 & 25.4 & 30.3 & 24.1 & 3.4 & 7.6 & 15.7 & 23.6 & 22.4 & 7.1 & 15.7 & 26.0 & 28.5 & 27.8 \\
\hline $10-19$ & 0.1 & 0.5 & 6.1 & 15.6 & 22.3 & 0.3 & 0.7 & 2.4 & 5.4 & 12.7 & 0.4 & 1.1 & 6.1 & 14.1 & 20.3 \\
\hline $20-29$ & 0 & 0 & 0.2 & 2.9 & 10.7 & 0.1 & 0 & 0.1 & 0.9 & 2.6 & 0.1 & 0.1 & 0.3 & 2.3 & 7.7 \\
\hline $30+$ & 0 & 0 & 0 & 0.3 & 7.8 & 0 & 0 & 0 & 0.1 & 1.9 & 0 & 0 & 0 & 0.1 & 5.6 \\
\hline
\end{tabular}

COPD Chronic obstructive pulmonary disease 
Figure 4, Top). A similar result was obtained in young adults ( $r=0.73$, Figure 4 , Middle), in whom spirometry rates varied from about $2 \%$ to $20 \%$, and asthma diagnosis rates varied from $4 \%$ to $19 \%$. In people aged 35 years and older, spirometry rates varied from $5 \%$ to $27 \%$, while the rates of physician-diagnosed obstructive disease varied from about $8 \%$ to nearly $30 \%$. Again, the frequency of spirometry was significantly correlated with the frequency of diagnosed obstructive disease ( $r=0.33$, Figure 4, Bottom), although there was more scatter than observed in the younger age groups.

\section{DISCUSSION}

We believe that we were able to access data on nearly all of the spirometric testing performed in Manitoba because of the strong fiscal incentive implicit in the billing process. We missed data on some hospital-based tests carried out by respiratory therapists who did not bill Manitoba Health, but these tests were likely carried out on patients who also had spirometry that was interpreted by physicians, and therefore, the patients were probably captured by the billing system. However, our estimates of the frequency of spirometric testing were, if anything, an underestimate.

The frequency of spirometric testing was recently studied in Ontario and found to vary substantially among regions (6). However, testing was not related to diagnoses or to individual patients, so no conclusions could be drawn regarding the appropriateness of the procedure (7).

Manitoba has one large city, Winnipeg, with about $60 \%$ of the provincial population, and a disproportionately rich supply of specialists and pulmonary function laboratories; a substantial fraction of the province's rural population lives close enough to Winnipeg to use Winnipeg facilities for much of its health care. For reasons that are not clear, the prevalence of physician-diagnosed obstructive diseases is higher in Winnipeg than in the remainder of the province (8). These factors probably account for the preponderance of testing in Winnipeg and that spirometry rates were higher in Winnipeg residents than in those from the remainder of the province. Nevertheless, in some of the 49 communities examined individually, greater fractions of the population were tested than in Winnipeg, and in these communities, the majority of tests were performed outside of Winnipeg, presumably locally. Thus, community spirometry rates appeared to reflect not only the influence of Winnipeg, but also whether the local family practitioners billed for the tests; where this occurred, spirometry rates were high. Despite these differences, age and sex distributions of the people tested did not differ between Winnipeg and rural areas, nor did the number of tests per patient tested; repeat tests were as common in rural residents as in residents of Winnipeg.

The sex distribution of spirometric testing mirrored the prevalence of obstructive disease. Asthma is more prevalent in boys than in girls, but the reverse is true for adults aged 15 to 59 years. COPD is largely a disease of people older than age 60 years, among whom it is very common, affecting men more than women. Spirometry rates in children were similar

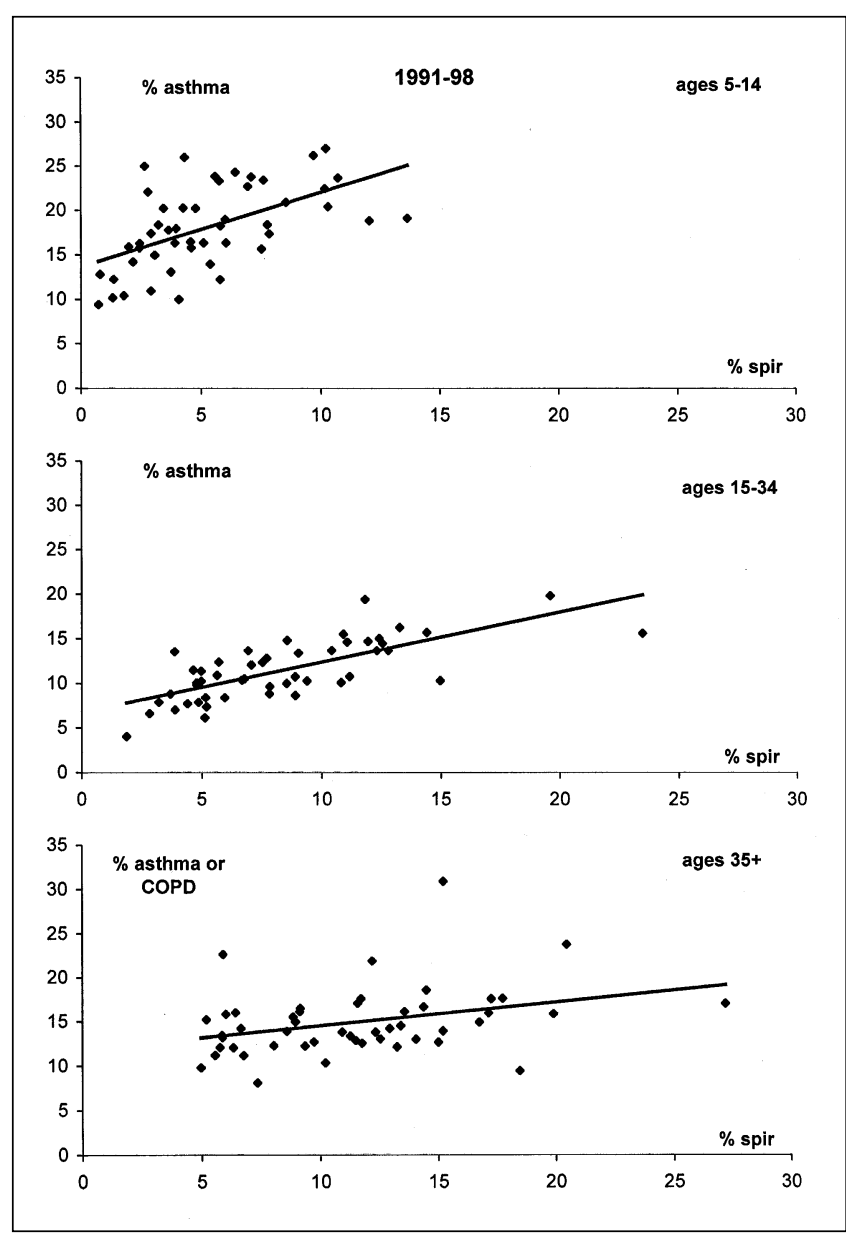

Figure 4) Regional comparison of spirometry rates (abscissas) with rates of physician-diagnosed obstructive diseases (ordinates) over the eight years of the study (1991 to 1998). Data from each of 49 service use regions are shown, and the percentages apply to residents of Manitoba in 1998. Top Spirometry rates are compared with asthma rates in children aged five to 14 years. Middle $A$ similar comparison is made in people aged 15 to 34 years. In both cases, the correlation was good (Top, $r=0.55$; Middle, $r=0.73$ ). Bottom Spirometry rates in people aged 35 years and older are compared with rates of obstructive diseases: asthma, chronic obstructive pulmonary disease (COPD), and both asthma and COPD. The correlation was significant, but less good $(r=0.33)$

to those of young adults (Figure 1), while children with asthma were tested less often than adults. This is accounted for by the relatively high prevalence of asthma in children. The relatively low rate of testing in children with asthma probably reflected the fact that some five- to 10-year-old children are very difficult to test with reliable results. In Winnipeg, there was a bias favouring the testing of children from upper income quintiles. This probably reflected referral patterns and not overall access to care, because physician visits for obstructive diseases were at least as common in children from low income quintiles as from other quintiles (9).

Many patients who had multiple visits for obstructive diseases had been tested at some time during the eight years 
we studied. The number of tests per patient increased with number of visits. The number of visits reflected a combination of disease severity and the fraction of the observation period that patients had the diagnoses of interest, and given the chronic nature of these diseases and the time frame used, multiple physician visits should not have been unusual. More than $60 \%$ of the patients who had more than 10 physician visits for asthma or COPD underwent spirometry, and of patients with more than 30 visits for asthma, and asthma and COPD, well over one-half of them had four or more tests. Of interest, among adults, spirometry rates in people labelled with asthma differed little from those labelled with both asthma and COPD, and both were distinctly higher than in people labelled with COPD only, irrespective of the number of physician visits. Indeed, 39\% of patients labelled with COPD who had more than 10 physician visits did not undergo any spirometry testing during the eight-year study period; this was the case for $25 \%$ of adults labelled with asthma and $22 \%$ of those labelled with both asthma and COPD.

Comparing our results quantitatively with other studies of spirometry use in the literature is difficult, given our sampling frame and that we were able to recover data from the whole province. However, previous studies of patient records for both asthma and COPD have concluded that spirometry was underused $(10,11)$. Further, surveys of physician attitudes have shown that primary care providers use spirometry much less than recommended in asthmatics (12-14). In the present study, about $60 \%$ of adults with 10 or more visits for asthma or asthma and COPD underwent spirometry at least twice; therefore, this aspect of their care may have been in accordance with guidelines. On the other hand, more than one-fifth of patients with 10 or more physician visits for these diagnoses did not undergo testing, and spirometry was used even less in patients labelled with COPD only. Thus, while one could argue that a substantial fraction of patients with obstructive disease, especially those labelled with asthma, underwent spirometry according to guidelines, it is indisputable that many patients did not, especially if they were labelled with COPD only. The present study therefore agrees with others, concluding that spirometry is underused. The publication of guidelines for obstructive diseases probably did not influence spirometry use in Manitoba, because there was no increase in testing in the years that we studied, which covered the guideline releases.

We hypothesized that when small areas were compared, spirometry use would correlate with the prevalence of physician-diagnosed obstructive disease, and this was the case (Figure 4). This is compatible with the finding that spirometry is important in making the diagnosis of obstruc- tive disease or, more likely, that spirometry use was indicative of physician sensitivity to the problem of obstructive disease. However, in people aged 35 years and older, area spirometry use and the rate of physician-diagnosed obstructive disease, including COPD, were less well related than spirometry and asthma rates in children and young adults. This was puzzling, because spirometry is a much better diagnostic test in patients with COPD than in patients with asthma, but it was consistent with our other data indicating that spirometry rates are higher in patients labelled with asthma, with or without the additional label of COPD, than they are for patients labelled with COPD only. Apparently, many Manitoba physicians are comfortable diagnosing and managing COPD without spirometry, although experts argue that spirometry defines the syndrome.

ACKNOWLEDGEMENTS: This study was supported by a grant from Boehringer-Ingelheim (Canada) Ltd.

\section{REFERENCES}

1. Boulet L-P, Becker A, Berube D, Beveridge R, Ernst P. Canadian Asthma Consensus Report, 1999. Canadian Asthma Consensus Group. CMAJ 1999;161(11 Suppl):SF1-14.

2. National Heart, Lung and Blood Institute, National Asthma Education Project. Expert Panel Report: Guidelines for the Diagnosis and Management of Asthma. NIH Publication No. 91-3042. Bethesda: US Department of Health and Human Services, 1991.

3. Standards for the diagnosis and care of patients with chronic obstructive pulmonary disease. American Thoracic Society. Am J Respir Crit Care Med 1995;152:S77-120.

4. Canadian Respiratory Review Panel. Guidelines for the Treatment of Chronic Obstructive Pulmonary Disease (COPD). Toronto: Medication Use Management Services Inc, 1998.

5. Roos NP, Fransoo R, Bogdanovich B, et al. Needs based planning for Manitoba's generalist physicians. Med Care 1999;37:S206-28.

6. Chan B, Anderson G, Dales RE. Spirometry utilization in Ontario: practice patterns and policy implications. CMAJ 1997;156:169-76.

7. Anthonisen NR. Spirometric testing: how much is enough? CMAJ 1997;156:202-4.

8. Erzen D, Mustard C, Manfreda J, Anthonisen NR. Regional, urban-rural and socioeconomic variation of asthma in Manitoba. Am J Respir Crit Care Med 1994;149:A915. (Abst)

9. Erzen D, Carriere KC, Dik N, et al. Income level and asthma prevalence and care patterns. Am J Respir Crit Care Med 1997;155:1060-5.

10. Doerschug KC, Peterson MW, Dayton CS, Kline JN. Asthma guidelines: an assessment of physician understanding and practice. Am J Respir Crit Care Med 1999;159:1735-41.

11. Ryland I, Kelly YJ, Bucknall C, Pearsom MG. Recording of spirometry in patients admitted with acute exacerbations of COPD. Am J Respir Crit Care Med 1999;159:A823. (Abst)

12. Picken HA, Greenfield S, Teres D, Hirway PS, Landis JN. Effect of local standards on the implementation of national guidelines for asthma. J Gen Intern Med 1998;13:659-63.

13. O'Dowd LC, Pannetteri RA Jr. Attitudes of physicians towards spirometry use in asthma. Am J Respir Crit Care Med 2000;161:A625. (Abst)

14. Boulet L-P, Phillips R, O'Byrne P, Becker A. Evaluation of asthma control by physicians and patients: comparison with current guidelines. Thorax. (In press) 


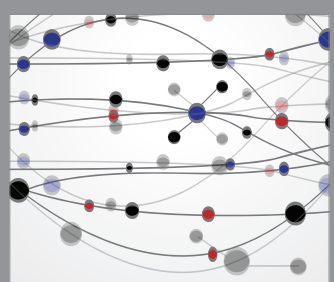

The Scientific World Journal
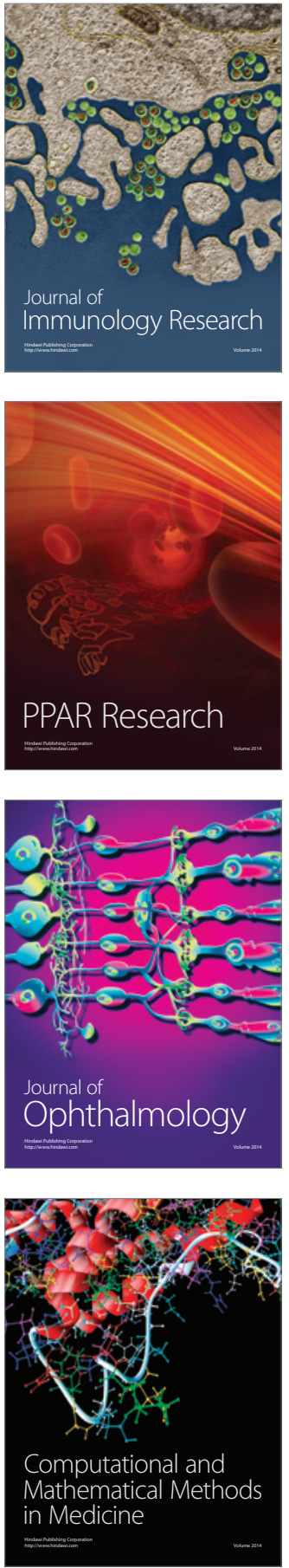

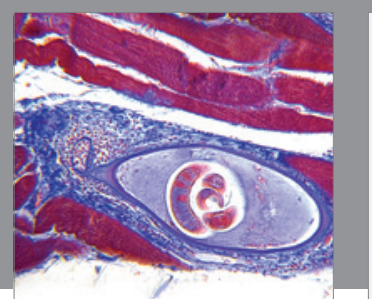

Gastroenterology Research and Practice

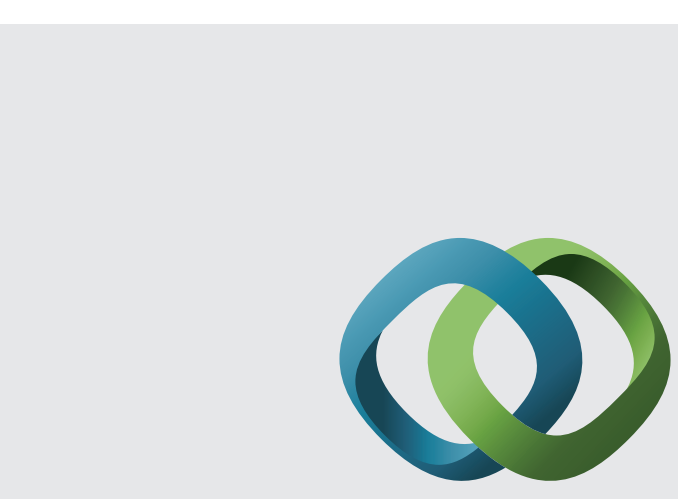

\section{Hindawi}

Submit your manuscripts at

http://www.hindawi.com
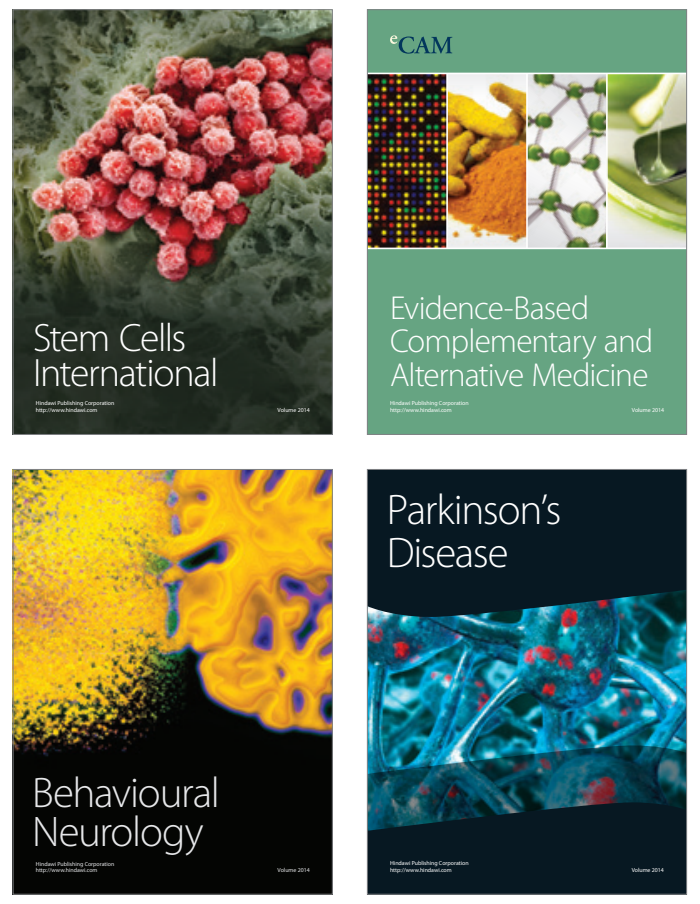
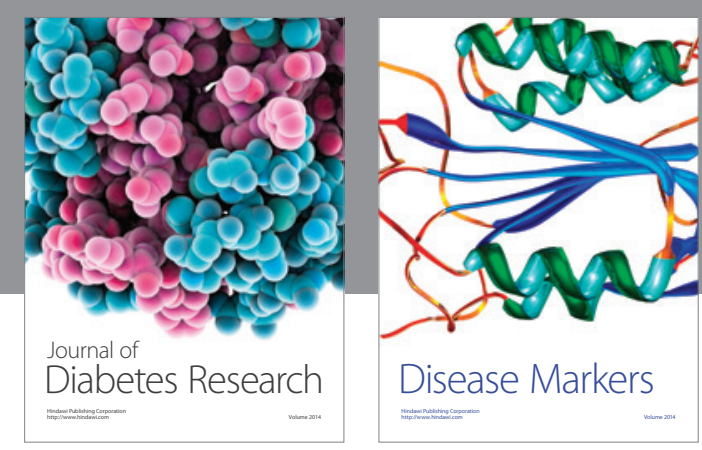

Disease Markers
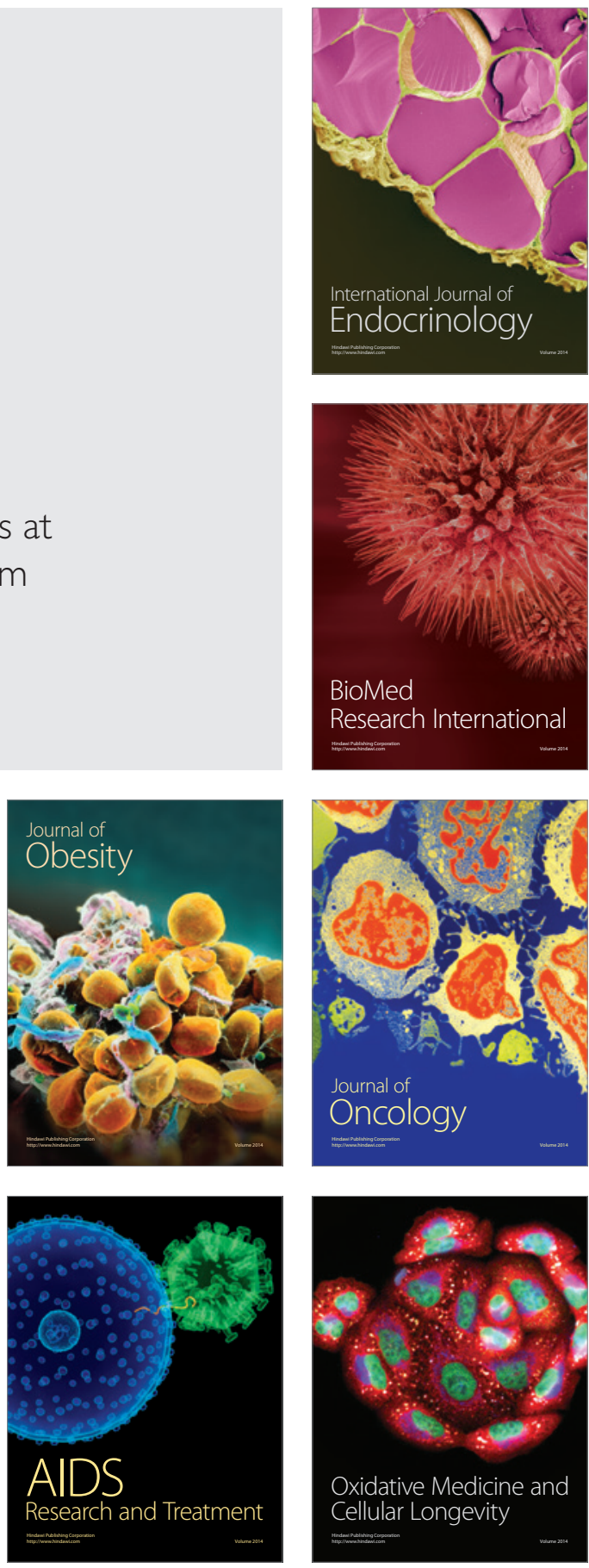